\title{
Femtosecond pulsed laser direct write production of nano- and microfluidic channels
}

\author{
Joel P. McDonald, ${ }^{\text {a) }}$ Vanita R. Mistry, Katherine E. Ray, and Steven M. Yalisove \\ Department of Materials Science and Engineering, University of Michigan, 2300 Hayward Street, \\ Ann Arbor, Michigan 48109-2136 and Center for Ultrafast Optical Science, University of Michigan, \\ 2200 Bonisteel Avenue, Ann Arbor, Michigan 48109-2099
}

(Received 11 January 2006; accepted 8 April 2006; published online 5 May 2006)

\begin{abstract}
Nano- and microfluidic channels were produced by selectively delaminating $1200 \mathrm{~nm}$ thermally grown oxide films $\left(\mathrm{SiO}_{2}\right)$ films from $\mathrm{Si}(100)$ substrates using a femtosecond pulsed laser. Single pass channels exhibiting bell-like cross sections with widths of $24 \mu \mathrm{m}$ and heights of $355 \mathrm{~nm}$ were directly written at a speed of $1 \mathrm{~cm} / \mathrm{s}$, while larger channels $(320 \mu \mathrm{m}$ in width and $\sim 15 \mu \mathrm{m}$ in height) were produced by laterally overlapping single pass channels. The results of an investigation of the interior surfaces of the channels via atomic force microscopy and scanning electron microscopy are presented. (C) 2006 American Institute of Physics. [DOI: 10.1063/1.2201620]
\end{abstract}

The presence or absence of the native oxide of $\mathrm{Si}(100)$ was found to influence both the femtosecond laser induced damage threshold (laser pulse energy required to produce damage) and damage morphology. ${ }^{1}$ To better understand the role of thin oxide films on femtosecond laser induced damage, damage studies were performed on $\mathrm{Si}(100)$ samples with thermally grown oxide ( $\mathrm{SiO} 2)$ films of a range of thicknesses $(20-1200 \mathrm{~nm}){ }^{2}$ Two primary damage morphologies were observed to result from irradiation with femtosecond laser pulses. For laser fluence $\left(\mathrm{J} / \mathrm{cm}^{2}\right)$ greater than $0.7 \pm 0.1 \mathrm{~J} / \mathrm{cm}^{2}$, the thermal oxide film was observed to be removed from the substrate in a nearly discrete fashion, resulting in craters of depth approximately equal to the thickness of the film. For low laser fluence $\left(<0.7 \pm 0.1 \mathrm{~J} / \mathrm{cm}^{2}\right)$, the thermal oxide film was observed to delaminate or buckle up from the $\mathrm{Si}(100)$ substrate forming a blisterlike feature. ${ }^{3,4}$ It was soon discovered that single isolated blisters could be connected together to form a connected region of delaminated film, ${ }^{5}$ such that capillaries or channels could be produced in which the top surface of the channel is the delaminated thermal oxide film and the bottom surface is the underlying $\mathrm{Si}(100)$ substrate. In this work, a single-step technique using a commercially available femtosecond pulsed laser for producing channels with nanometer and micrometer dimensions is presented.

The nano- and microfluidic channels were produced on Si(100) wafers with $1200 \mathrm{~nm}$ thermally grown oxide films. The thickness of the film was determined via ellipsometry. Samples were prepared for channel production by an initial degreasing scrub, followed by acetone, methanol, and deionized water baths. The source of the laser pulses was a commercially available laser (CPA 2001, Clark MXR), that produced pulses with temporal width of $150 \mathrm{fs}$, at a repetition rate of $1 \mathrm{kHz}$. Each laser pulse had a central wavelength of $775 \mathrm{~nm}$, and an energy of $800 \mu \mathrm{J}$. The optics setup used to deliver the laser beam to the sample surface is presented in Fig. 1. The sample motion was controlled using a three-axis motorized translation stage. To produce a single pass channel, the sample was scanned at a constant velocity of $1 \mathrm{~cm} / \mathrm{s}$ a) Author to whom correspondence should be addressed; electronic mail:
jpmcdona@umich.edu along a straight path through the focused laser beam. The laser fluence found to produce the most uniform capillaries was $0.35 \mathrm{~J} / \mathrm{cm}^{2}$. To produce wider capillaries, single pass capillaries were overlapped laterally with a $15 \mu \mathrm{m}$ separation. A schematic of the writing technique is also presented in Fig. 1. Channels were characterized with optical microscopy (OM), atomic force microscopy (AFM), and scanning electron microscopy (SEM).

Examples of capillaries generated with the femtosecond laser direct write technique are presented in Fig. 2. Up to a width of around $100 \mu \mathrm{m}$, the channels exhibit a bell-like cross section (specifically an Euler mode), while for capillaries of width exceeding $100 \mu \mathrm{m}$, the top surface of the channel (i.e., the delaminated thermal oxide film) exhibited the so-called telephone cord mode. ${ }^{6}$ A range of channel geometries were pursued, including intersections and corners as presented in Fig. 3. The height of a given channel was found to be a function of its width, such that the total volume of the channel could be fine tuned by carefully controlling its lateral dimensions (see Fig. 4). Channels with the Euler mode

(a) Optical Setup

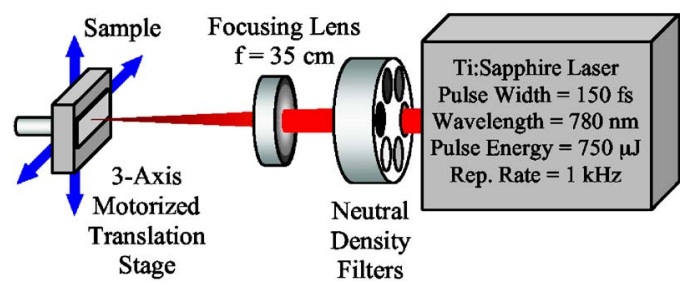

(b) Capillary Writing Technique

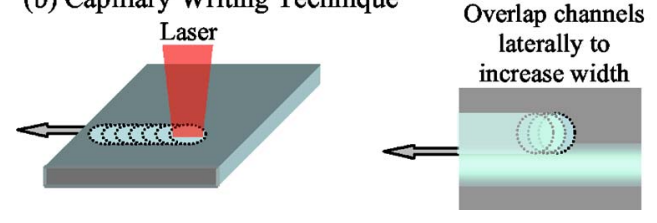

FIG. 1. (Color online) Experimental Details. (a) Optical setup to deliver laser to sample surface. (b) Linear channel writing method: single pass channel was generated by translating the sample through the focus of the laser beam at a speed of $1 \mathrm{~cm} / \mathrm{s}$ (indicated by arrow to the left), such that individual blisters overlap and a channel is produced. To produce larger channels, single pass capillaries are overlapped laterally at a separation of $15 \mu \mathrm{m}$. 

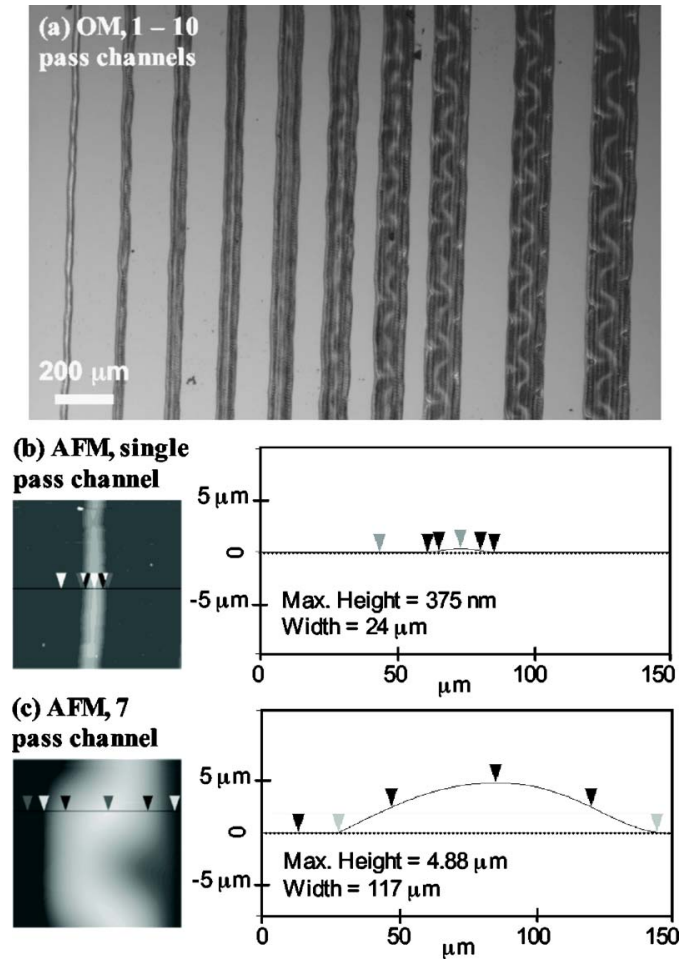

FIG. 2. (Color online) Examples of femtosecond laser direct write fluidic channels made with a laser fluence of $0.35 \mathrm{~J} / \mathrm{cm}^{2}$. (a) OM image of channels produced with a single pass on the left up to ten overlapped passes on the right. Single to five pass channels exhibit the Euler-type mode, while the telephone cord mode emerges for six and greater passes. (b) AFM section analysis of channel produced with a single pass at a speed of $1 \mathrm{~cm} / \mathrm{s}$. (c) AFM section analysis of a channel produced with seven passes overlapped laterally with a spacing of $15 \mu \mathrm{m}$ exhibiting the telephone cord mode.

were generated with widths of 24-95 $\mu \mathrm{m}$, and peak heights of $355 \mathrm{~nm}-3.94 \mu \mathrm{m}$, respectively (measured via AFM). The dimensions of capillaries with width exceeding $150 \mu \mathrm{m}$ or height exceeding $6.2 \mu \mathrm{m}$ were not measured as their dimensions exceeded the maximum measurable limits of the AFM. However, given the height dependence on width presented in Fig. 4, we expect the channel height to exceed $15 \mu \mathrm{m}$ at a width of $320 \mu \mathrm{m}$.

To determine if the channels were capable of carrying fluid, drops of water were placed near the edge of a sample on which linear channels of a range of sizes had been written off the edge of the sample surface. Viewed through an optical microscope, the channels were observed to fill with water, presumably by capillary action. Movies were collected at a rate of 30 frames/s (yielding a resolution of $1.6 \mathrm{~mm} / \mathrm{s}$ for velocity determination) of the capillaries filling with water, and these movies were subsequently analyzed to obtain flow rates. The flow rate was found to increase with increasing channel width, such that channels of widths $105-320 \mu \mathrm{m}$ were found to exhibit flow rates of $6.2-17.5 \mathrm{~mm} / \mathrm{s}$, respectively $( \pm 1.6 \mathrm{~mm} / \mathrm{s})$.

The interior surfaces of the channels were characterized using AFM and SEM. Due to the absorption of the laser energy at the substrate-film interface, the substrate was modified during production of the channels resulting in some roughening of the substrate surface. The roughness of the substrate at the bottom of a popped channel (when the laser fluence was too high, the delaminated thermal oxide film was completely removed from the wafer during production) was measured via AFM, yielding a rms roughness of $59 \mathrm{~nm}$ (see

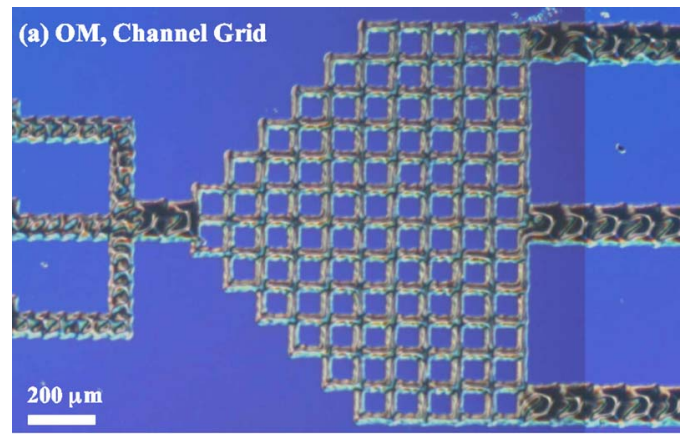

(b) AFM, Intersection

(c) AFM, Corners

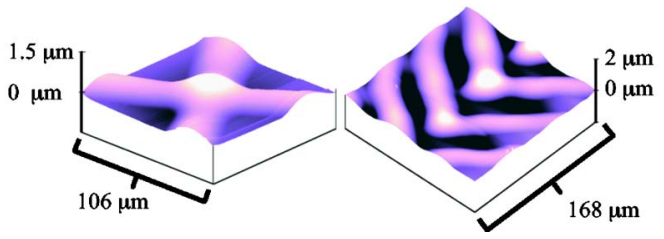

FIG. 3. (Color online) Examples of channel variations produced with femtosecond laser direct write technique. (a) OM image obtained in Nomarski mode of grid network produced in $1200 \mathrm{~nm}$ thermal oxide on $\mathrm{Si}(100)$. (b) AFM topographic image of intersection of two channels. (c) AFM topographic image of series of channel corners.

Fig. 5). The roughness of the substrate for a channel produced under optimal laser conditions is expected to exhibit less roughness than that of the popped channel, as under optimal conditions, the net energy deposited by the laser into the material is half of that deposited when the channel was observed to pop. The roughness at the bottom surface of the delaminated glass (observed via SEM) was less than $5 \mathrm{~nm}$. It is expected that the bottom surface of the channel will exhibit surface qualities of $\mathrm{SiO}_{2}$ as the native oxide of $\mathrm{Si}$ is expected to grow within a millisecond of the initial exposure of the substrate to oxygen.

The mechanism responsible for the delamination of the film from the underlying substrate is thought to rely on the location at which the incident laser energy is absorbed upon encountering the sample surface. As the thermal oxide is largely transparent to the wavelength of the incident laser pulse, the laser pulse is expected to traverse the glass with little modification and deposit its energy entirely in the $\mathrm{Si}(100)$ substrate. ${ }^{3,4}$ The absorption of the laser energy and subsequent melting of the $\mathrm{Si}(100)$ at the substrate-film interface produces the initial delamination of the thermal oxide film. Although the film does not directly absorb the energy of

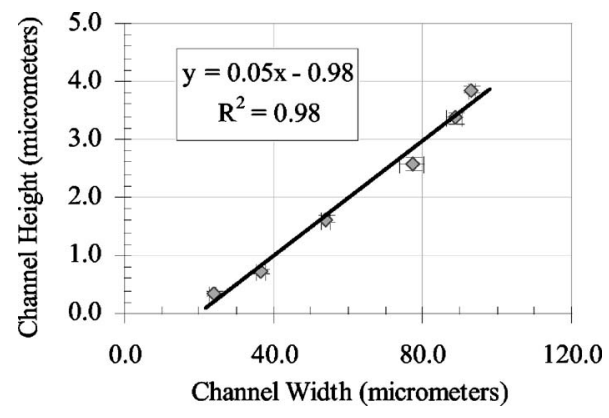

FIG. 4. The plot above shows the measured channel height as a function of its width. It should be noted that these measurements were restricted to the Euler-type modes, as the telephone cordlike modes possessed heights exceeding the measurable limits of the AFM used for the analysis. The results of a linear fit are presented in the plot. 

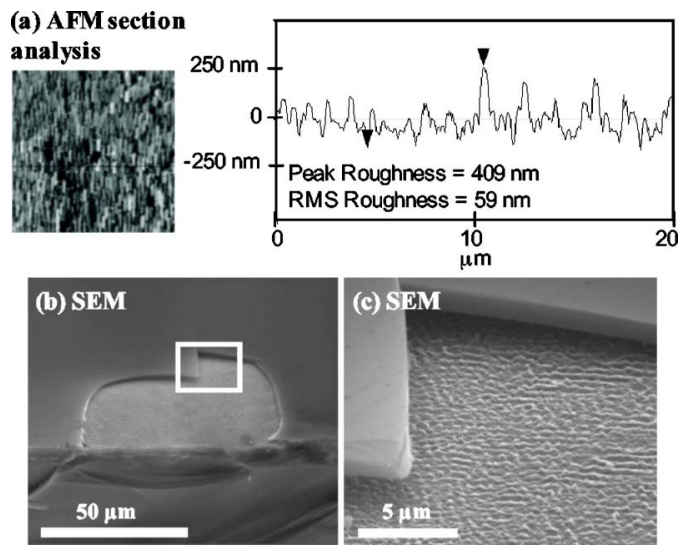

FIG. 5. (Color online) Surface roughness of channel interior. (a) AFM section analysis of bottom surface of a popped channel indicating a peak roughness of $409 \mathrm{~nm}$ and a rms roughness of $59 \mathrm{~nm}$. The width of the image at left is $20 \mu \mathrm{m}$. The net laser energy deposited into the substrate for the channel shown is twice the laser energy used to produce channels under optimal conditions. (b) SEM image (tilt $=59^{\circ}$ ) of the end of channel written off the edge of a sample. The bottom surface of the channel was exposed by intentionally fracturing the delaminated glass at the edge of the wafer. The inset shows the location of the image shown in (c), a SEM image showing laser induced roughness of the substrate.

the incident laser pulse, it is thought that the film is heated and softened both by its proximity to the molten substrate and by the dense electron plasma produced upon the initial absorption of the laser energy by the $\mathrm{Si}(100)$ substrate. ${ }^{7}$ Once delaminated, the film expands upward from the substrate due to a combination of relaxation of compressive stress present in the film and the transfer of momentum from the material ablated by the action of the incident laser pulse. ${ }^{8,9}$ At laser fluences in excess of $0.7 \pm 0.1 \mathrm{~J} / \mathrm{cm}^{2}$, it is presumed that the force applied on the film by the expanding ablated substrate material exceeds the shear strength of the film, resulting in the complete removal of the film from the substrate.

In contrast with other direct write techniques for producing fluidic channels, the method presented here has the advantage of involving only a single processing step for channel production. ${ }^{10}$ Additionally, in contrast to bulk femtosecond laser machining of channels, ${ }^{11,12}$ there is very little debris generated during channel production so that channels are not clogged while they are produced. The method presented here produces channels of noncircular cross section, in contrast to circular channels produced with other techniques, ${ }^{10,12}$ and there is greater roughness on the substrate surface relative to the channels produced in Ref. 10. Furthermore, the delaminated thermal oxide film was fragile, particularly for large channels where broad sections of thermal oxide film were delaminated. The durability of the delaminated films can be enhanced by embedding the entire chip in poly(dimethylsiloxane) (PDMS), a processing step which also provides for the addition of fluid input and output reservoirs. A quantification of the strength of the delaminated films is the topic of future work.

In summary, a direct write process for the production of nano- and microfluidic channels has been demonstrated using a femtosecond pulsed laser to selectively delaminate $1200 \mathrm{~nm}$ thermal oxide films from $\mathrm{Si}(100)$ substrates. Single pass channels with bell-like cross sections were directly written at a rate of $1 \mathrm{~cm} / \mathrm{s}$ with a width of $24 \pm 1 \mu \mathrm{m}$ and height of $355 \pm 45 \mathrm{~nm}$, while larger channels up to $320 \mu \mathrm{m}$ in width were created by laterally overlapping single pass channels. The rms roughness of the substrate surface of a popped channel was measured via AFM to be $59 \mathrm{~nm}$, and the roughness of substrate surface for a channel produced under optimal conditions is expected to be at least a factor of two less. It should be noted that the laser pulse energy required to produce fluidic channels with the femtosecond laser direct write technique is a modest $4.6 \mu \mathrm{J}$, or an average laser power of $4.6 \mathrm{~mW}$ for a $1 \mathrm{kHz}$ repetition rate amplified femtosecond pulsed laser. Although demonstrated as a serial technique, parallel processing could be achieved by splitting a single laser beam into several beam lines, each capable of producing fluidic channels on the same or different substrates controlled by a common translation stage. The femtosecond laser direct write technique for producing nano- and microfluidic channels presented here may be a useful alternative to traditional multistep lithography-based techniques, ${ }^{6}$ and due to the convenient $\mathrm{SiO}_{2}$ on $\mathrm{Si}$ structure, the technique may be ideally suited for incorporating electronic sensing and fluid manipulation into fluidic or micro electro-mechanical systems (MEMS).

This work was funded by the NSF (Grant No. DMR03070400) and the DARPA/AFOSR (Grant No. FA9550-04-0136).

${ }^{1}$ J. P. McDonald, A. A. McClleland, Y. N. Picard, and S. M. Yalisove, Appl. Phys. Lett. 86, 264103 (2005).

${ }^{2}$ J. P. McDonald, V. R. Mistry, K. E. Ray, and S. M. Yalisove, Mater. Res. Soc. Symp. Proc. 875, O.12 (2005).

${ }^{3}$ J. R. Serrano and D. G. Cahill, J. Appl. Phys. 92, 7606 (2002).

${ }^{4}$ J. R. Serrano and D. G. Cahill, Microscale Thermophys. Eng. 9, 155 (2005).

${ }^{5}$ K. Xiao, Z. S. Guan, G. J. Wang, L. Jiang, D. B. Zhu, and Y. R. Wang, Appl. Phys. Lett. 85, 1934 (2004).

${ }^{6}$ M. W. Moon, K. R. Lee, K. H. Oh, and J. W. Hutchinson, Acta Mater. 52, 3151 (2004).

${ }^{7}$ B. Rethfeld, K. Sokolowski-Tinten, D. Von der Linde, and S. I. Anisimov, Appl. Phys. A: Mater. Sci. Process. 79, 767 (2004).

${ }^{8}$ D. von der Linde and K. Sokolowskit-Tinten, Appl. Surf. Sci. 154, 1 (2000).

${ }^{9}$ J. P. McDonald, V. R. Mistry, K. E. Ray, J. A. Nees, N. R. Moody, and S. M. Yalisove, Appl. Phys. Lett. 88, 153121 (2006).

${ }^{10}$ D. Therriault, S. R. White, and J. A. Lewis, Nat. Mater. 2, 265 (2003).

${ }^{11}$ T. N. Kim, K. Campbell, A. Groisman, D. Kleinfeld, and C. B. Schaffer, Appl. Phys. Lett. 86, 201106 (2005).

${ }^{12}$ K. Ke, E. F. Hasselbrink, and A. J. Hunt, Anal. Chem. 77, 5083 (2005). 